\title{
Prevalence of second canal in the mesiobuccal root of permanent maxillary molars from a Turkish subpopulation: a cone-beam computed tomography study
}

\author{
G. Magat, S. Hakbilen \\ Department of Oral and Maxillofacial Radiology, Faculty of Dentistry, Necmettin Erbakan University, Konya, Turkey
}

[Received: 19 July 2018; Accepted: 19 September 2018]

\begin{abstract}
Background: Permanent maxillary molar teeth have the most complex root and canal systems. This study aimed to determine the frequency and the localisation of secondary mesiobuccal canal (MB2) in the mesiobuccal roots of permanent maxillary molars in a Turkish subpopulation using cone-beam computed tomography (CBCT) and compare them by different age groups and gender.

Materials and methods: In this retrospective study, a total of 800 maxillary molar teeth in 200 subjects were investigated. The distances between canals were calculated from the centre point of the MB2 canal (PMB2) to the centre point of the mesiobuccal canal (PMB1) and the centre point of the palatal canal (PP).

Results: The incidence of MB2 canals was found to be $33.5 \%$ (23.2\% in females, $43.6 \%$ in males) in 200 subjects. A significant difference was found between age groups and genders in terms of the frequency of MB2 $(p<0.05)$. The distances between PMB1$-P M B 2$ were $2.95 \pm 0.58 \mathrm{~mm}, 3.08 \pm 0.67 \mathrm{~mm}$ for $1 \mathrm{MM}$ and $2 \mathrm{MM}$, respectively. For $1 \mathrm{MM}$ and $2 \mathrm{MM}$, the averages of PMB2-PP distances were $5.81 \pm 1.09 \mathrm{~mm}$ and $5.55 \pm 1.09 \mathrm{~mm}$, respectively. The contralateral formation of the MB2 canals was $90.5 \%$ $(16,26)$ in the first molars and $93.9 \%$ in the second molars $(17,27)$. The contingency rate in the first quadrant was $86.0 \%(16,17)$ and $83.5 \%(26,27)$ in the second quadrant. Conclusions: It is important for the clinician to know the high probability of finding the MB2 canal in the maxillary first and second molars. CBCT imaging can facilitate the clinician to detect complex and variable root canal anatomy. (Folia Morphol 2019; 78, 2: 351-358)
\end{abstract}

Key words: maxillary molars, secondary mesiobuccal canal, cone-beam computed tomography

\section{INTRODUCTION}

The success of endodontic treatment relies on the complete cleaning, shaping, and filling of the entire root canal system to prevent recontamination. One of the endodontic treatment failures is the presence of an additional canal in the teeth $[1,13]$. For this reason, detailed information of the morphology of the root canals is of great importance. Given the broad individual, genetic and ethnic diversity, clinicians should seek extra canals $[29,47]$.

Permanent maxillary molar teeth have the most complex root and canal systems [3, 52]. Their canal system is very diverse [7]. The high failure rate stems from the impossibility of locating the presence and location of the secondary mesiobuccal canal (MB2) in the mesiobuccal roots of the permanent maxillary

Address for correspondence: Assist. Prof. Dr. G. Magat, Necmettin Erbakan University Dentistry Faculty Oral Radiology Department, Konya, Turkey, tel: +90 50594561 57, e-mail: gul_dent@hotmail.com 
molars [9]. Due to excessive dentin accumulation in opening the canal and difficulty of visualisation of molar teeth, its location in clinical practice is quite complicated [7]. Throughout the literature, the presence of the MB2 canal ranges from $18.6 \%$ to $96.1 \%$ $[20,22,31]$. When the MB2 canal cannot be located or properly treated, it may contribute to continued patient pain or root canal failure [52].

The MB2 canals are visualised by histological sections [44], diaphanisation [17], magnifying loupes [41], endodontic surgical microscope [26], scanning electron microscope [44], periapical radiography [40], micro-computed tomographic analysis $[27,51]$, and cone-beam computed tomography (CBCT) [7-9, 57, 58]. However, some of these techniques are invasive, disadvantageous and can only be used to investigate extracted teeth [50]. Nowadays, CBCT has become more widely used because it can provide more reliable diagnostics in the field of endodontics $[11,23$, 34] and can perform morphological analysis of the root canal system $[9,30,32,37,58]$. The American Association of Endodontists (AAE) and the European Society of Endodontology (ESE) have released position statements stating that limited field of view CBCT should be considered the imaging modality of choice for initial endodontic treatment of teeth with the potential for extra canals and suspected complex morphology (AAE and AAOMR Joint Position Statement 2015, ESE 2014). The studies confirm that the CBCT images are as accurate as the modified staining technique to describe the root canal system and far more accurate than periapical radiographs [37].

In the literature, there were several studies using the $\mathrm{CBCT}$ to investigate the prevalence and morphology of the MB2 canal of permanent maxillary molars in various ethnicities $[16,19,25,45,49,58]$. However, there were not sufficient studies that evaluated the MB2 canal and its geometric localisation in Turkish population using CBCT. In addition, there are no reports about the symmetry in the MB2 canal between contralateral and adjacent molars in a Turkish population. In this regards, this study aimed to determine (i) the frequency and (ii) the geometric localisation of MB2 canal (distances between the canals) in the mesiobuccal roots of permanent maxillary molars from a Turkish subpopulation using CBCT and (iii) compare them by different age groups and gender.

\section{MATERIALS AND METHODS}

The present study was approved by the Human Research Ethics Committee of the Faculty of Dentistry,
Necmettin Erbakan University, Konya, Turkey (decision no: 2018.01). In this retrospective study, CBCT images from 200 subjects were acquired from the archive of Oral and Maxillofacial Radiology Department, Faculty of Dentistry, Necmettin Erbakan University, Konya, Turkey. The CBCT images were obtained from January 2014 to December 2017 for diagnosis and dental treatment. For this study, we investigated CBCT images of 625 subjects. However, only 200 CBCT images were evaluated because of our inclusion criteria. The CBCT images of 101 men and 99 women between 13 and 67 years old were enrolled according to following criteria; (i) maxillary permanent molars with fully erupted and matured apices; and (ii) no root canal fillings, caries, posts, crown restorations, apical periodontitis, resorption, calcification or any pathology.

The 3D Accuitomo CBCT machine (J Morita Manufacturing Corp, Kyoto, Japan) was operated at $90 \mathrm{kVp}$ and $5 \mathrm{~mA}$ with a 17.5-second exposure time with a $100 \times 100 \mathrm{~mm}$ field of view, and with a $0.25 \times$ $\times 0.25 \mathrm{~mm}$ voxel size. All images were taken by oral and maxillofacial radiologists with $5+$ years of experience according to the manufacturer recommendations. A total of 400 maxillary permanent first molars and 400 maxillary permanent second molars were analysed using the $\mathrm{CBCT}$ machine software programme (i-Dixel, J Morita Manufacturing Corp, Kyoto, Japan) on the axial plane at $0.5 \mathrm{~mm}$ intervals and a $1 \mathrm{~mm}$ thickness. The examination was made from the coronal to apical. To standardise the observation and measurements, the MB2 was searched in a $1 \mathrm{~mm}$ apical of the pulp chamber floor (Fig. 1).

The distances between canals were calculated in millimetres from the centre point of the MB2 canal (PMB2) to the centre point of the mesiobuccal canal (PMB1) and the centre point of the palatal canal (PP) (Fig. 2) according to the protocol described by Betancourt et al. [7, 8].

The images were analysed by licensed oral and maxillofacial radiologist (S.H.) with 4 years' experience and previous training, and using consensus. The same investigator examined the radiographs twice in a period of 1 month and the intra-observer variability was calculated. The data collected in terms of gender, age, side, and distances between the different points were recorded.

\section{Statistical analysis}

The software SPSS/PC + v. 21.0 (SPSS, Chicago, IL) was used for statistical analysis. The descriptive statistics (mean \pm standard deviation), the $\chi^{2}$ test 


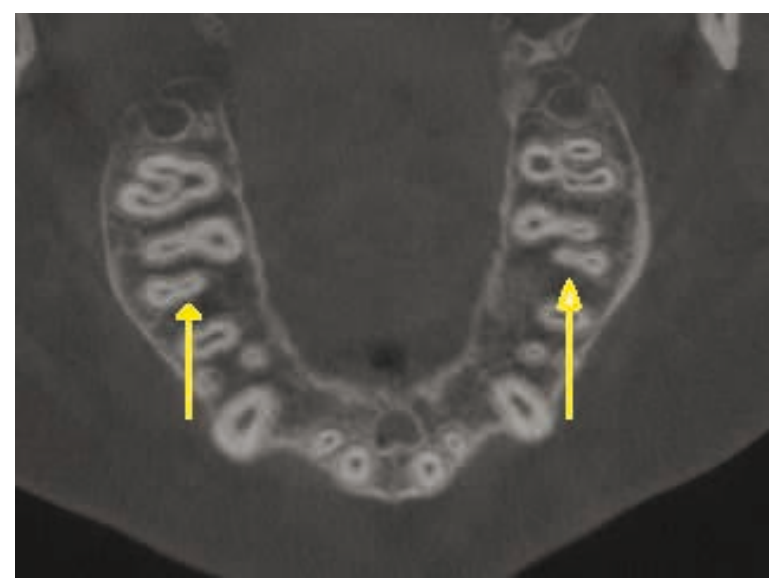

Figure 1. Axial view of cone-beam computed tomography (CBCT) images of maxillary first molars with secondary mesiobuccal canals (MB2) (arrows).

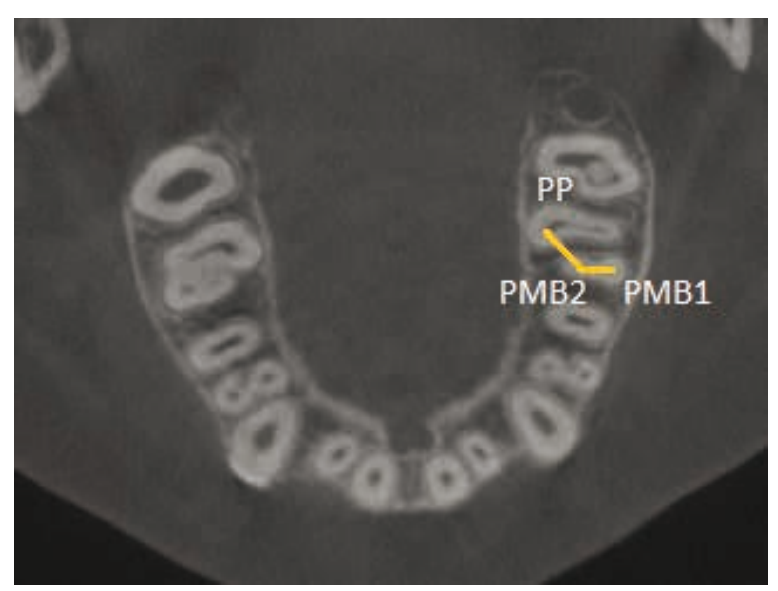

Figure 2. Axial view of left maxillary first molar. The distance in the lines drawn between the points was measured in millimetres; PMB1 - centre of mesiobuccal canal; PMB2 - centre of secondary mesiobuccal canal; $\mathrm{PP}$ - centre palatal canal.

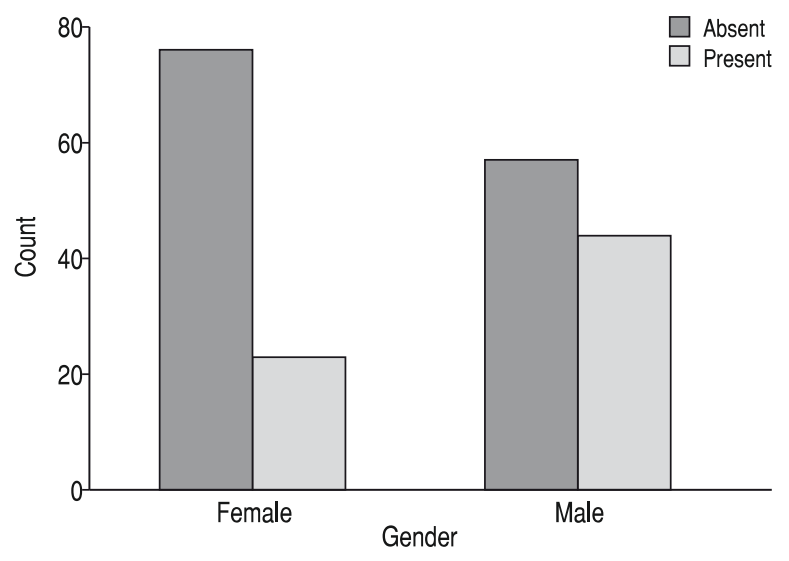

Figure 3. The frequency of secondary mesiobuccal canals according to gender. and the Spearman correlation tests were used. The reliability of data was analysed using the kappa test. A value of $p<0.05$ was considered significant.

\section{RESULTS}

In this retrospective CBCT-based study, 400 maxillary first molar and 400 maxillary second molar teeth were examined in 200 subjects (400 men and 99 women). The age range of the individuals was 13-67 years and the mean age was $29.45 \pm 11.73$ years. The kappa values for intra-observer reliability were ranged from 0.90 to 0.96 . The incidence of MB2 canals was found to be $33.5 \%$ ( $23.2 \%$ in females, $43.6 \%$ in males) in 200 subjects. The prevalence of the MB2 canal was $19.65 \%(n=79)$ and $17.70 \%$ $(n=71)$ in the first maxillary molars (1MM) and the second maxillary molars (2MM), respectively. MB2 canals had a homogeneous distribution of $49.5 \%$ on the right and $50.5 \%$ on the left. The total MB2 prevalence was $18.7 \%$ if we assessed on tooth basis.

These MB2 canals were in 44 males and 23 females. There was a statistically significant difference according to the gender ( $p=0.002 ;$ Fig. 3). Males had more prevalence of MB2 than females (Table 1).

The average age of the individuals with MB2 canal was $25.38 \pm 10.16$ years. MB2 canal prevalence of permanent maxillary molars according to age groups was shown in Table 2. Pearson $\chi^{2}$ test revealed that as the age progressed, the prevalence of MB2 was decreased $(p=0.001)$.

The average distances between PMB1-PMB2 were $2.95 \pm 0.58 \mathrm{~mm}, 3.08 \pm 0.67 \mathrm{~mm}$ for $1 \mathrm{MM}$ and $2 \mathrm{MM}$, respectively. For $1 \mathrm{MM}$ and $2 \mathrm{MM}$, the averages of PMB2-PP distances were $5.81 \pm 1.09 \mathrm{~mm}$ and $5.55 \pm 1.09 \mathrm{~mm}$, respectively.

The contralateral and adjacent occurrence probability for each tooth position was calculated between patients with MB2 canals. The contralateral formation of the MB2 canals was $90.5 \%(16,26)$ in the first permanent maxillary molars and $93.9 \%$ in the second permanent maxillary molars $(17,27)$. The contingency rate in the first quadrant was $86.0 \%$ $(16,17)$ and $83.5 \%(26,27)$ in the second quadrant. Table 3 shows the validity rates of an existing MB2 canal to estimate the MB2 canal on the contralateral side. The possibility of contralateral occurrence of MB2 canals in permanent first maxillary molar teeth $(16,26)$ was considerably better than for other tooth positions. Their sensitivity was $93.9 \%$ and positive 
Table 1. Prevalence of secondary mesiobuccal canals in the first and second permanent maxillary molars according to gender

\begin{tabular}{lcccc}
\hline Gender & Tooth 16 & Tooth 26 & Tooth 17 & Tooth 27 \\
\hline Female $(\mathrm{n}=100)$ & $9.1 \%$ & $12.1 \%$ & $13.1 \%$ & $14.1 \%$ \\
Male $(\mathrm{n}=100)$ & $28.7 \%$ & $28.7 \%$ & $21.8 \%$ & $21.8 \%$ \\
\hline
\end{tabular}

Table 2. Prevalence of secondary mesiobuccal canals in the first and second permanent maxillary molars according to age

\begin{tabular}{lcccc}
\hline Age [years] & Tooth 16 & Tooth 26 & Tooth 17 & Tooth 27 \\
\hline $13-25(n=88)$ & $27.3 \%$ & $30.7 \%$ & $22.7 \%$ & $25.0 \%$ \\
$26-40(n=62)$ & $14.5 \%$ & $16.1 \%$ & $17.7 \%$ & $16.1 \%$ \\
$>40(n=50)$ & $10.0 \%$ & 8.05 & $8.0 \%$ & $8.0 \%$ \\
\hline
\end{tabular}

Table 3. Probability accuracy assessment of secondary mesiobuccal canals (MB2) in different tooth positions

\begin{tabular}{|c|c|c|c|c|}
\hline \multirow[b]{2}{*}{ Test values } & \multicolumn{2}{|c|}{ Probability of an MB2 canal in the contralateral tooth } & \multicolumn{2}{|c|}{ Probability of an MB2 canal in the adjacent tooth } \\
\hline & $16 / 26$ & $17 / 27$ & $16 / 17$ & $26 / 27$ \\
\hline Sensitivity & $90.5 \%$ & $93.9 \%$ & $86.0 \%$ & $83.5 \%$ \\
\hline Specificity & $56.0 \%$ & $69.4 \%$ & $42.8 \%$ & $38.9 \%$ \\
\hline Positive predictive value & $88.8 \%$ & $93.3 \%$ & $87.6 \%$ & $86.2 \%$ \\
\hline Negative predictive value & $60.5 \%$ & $71.4 \%$ & $39.5 \%$ & $34.1 \%$ \\
\hline False-positive result & $11.2 \%$ & $6.7 \%$ & $12.4 \%$ & $13.8 \%$ \\
\hline False-negative result & $9.5 \%$ & $6.1 \%$ & $14.0 \%$ & $16.5 \%$ \\
\hline
\end{tabular}

predictive value was $93.3 \%$. Their false-positive and false-negative results were lowest.

The intraclass correlation coefficient scores of the intra-observer agreement were found to be 0.862 , $0.879,0902,0.880,0.895$ and 0.901 for distances and absent-present of MB2.

\section{DISCUSSION}

A comprehensive knowledge of root canal morphology and possible variations is a prerequisite for successful endodontic treatment. Anatomical variations should be examined both clinically and radiologically. Endodontic therapy should be initiated with proper preparation to allow access to the cavity; this can facilitate the investigation and successful detection of all root canal holes [10].

Detection of all channels in the root canal system and adequate clearing of these channels affect the ultimate success of treatment. For this reason, each tooth should be considered to have an extra channel. If possible, all extra canals should be detected [41]. MB2 canal was chosen as a parameter for this study because it is widely common [31], but the detection can be difficult in many patients $[21,46]$.

The permanent molars may have more than one or two canals of the first and second molar mesiobuccal root; can also be separated from various sides and may have lateral openings [14]. Vertucci [52] proposed a classification involving eight different types, while Weine et al. [53] studied root canal anatomy by separating one or two channels into four groupings. However, we have not classified the teeth according to any of these classification systems. Only, this retrospective study provides MB2 prevalence of maxillary molar teeth using $\mathrm{CBCT}$ images based on age and gender.

There are too many techniques in literature to visualise the accessory canals [17, 26, 41, 44]. Although the enlargement systems are useful for finding the $M B 2$ canal, they show only the average orifice of the MB2 canal, not the entire root canal system. However, if the pulp cavity is not opened sufficiently, the MB2 channel cannot be detected by magnification. For inclined or rotated molar teeth, the magnification is less effective because of a sharp and moder- 
ate angle of the tooth [8]. Stopko [46] stated that these microsurgical devices alone are inadequate to find and measure the MB2 canal. Moreover, the most commonly used method for the detection of accessory canals in everyday practice was periapical radiographs. They are important for endodontic preoperative diagnosis. However, they can only provide two-dimensional information limits the diagnostic efficiency. In addition, anatomical constructions are difficult to interpret in terms of factors such as superimposed anatomical structures, increased zygomatic bone density, or embedded teeth [39]. Barton et al. [5] and Abuabara et al. [2] reported the frequency of MB2 canals in molar teeth was $39.2 \%$ and $8 \%$, respectively. They noted that the effectiveness of conventional periapical X-rays was low. Nattress and Martin [35] stated that buccolingual radiographs alone were not reliable for detecting multiple canals. The use of CBCT imaging is not recommended for all endodontic treatment situations. At the same time, recent studies have shown that $\mathrm{CBCT}$ imaging shows excellent accuracy values compared to periapical radiographs [54]. For this reason, it is very important to know and use additional tools to help diagnose MB2 canal detection.

The incidence of MB2 canals in $1 \mathrm{MMs}$ and $2 \mathrm{MMs}$ varies from $8.0 \%$ to $96.1 \%[4,35,47,55-57]$. In this study, the prevalence of MB2 was $18.75 \%$, which is lower than some studies $[4,7,12,31,38,42]$. Studebaker et al. [47] found that an additional canal was $11.7 \%$ in CBCT images compared to other techniques. Silva et al. [45] reported that the MB2 canal incidence was higher than in first molars than in second molars (42-34\%). These differences may result from sample size, methodology and ethnic differences. Alexander et al. [4] stated that the reason of differences between results obtained from $C B C T$ may be $C B C T$ parameter settings and software differences. In addition, detection of the MB2 canals is probably difficult due to the dentin cap covering the orifice $[15,24]$. Another difficulty is that some of these canals can be curved. Their coronal part may contain one or two sudden folds $[22,31]$. This may explain the fact that MB2 canals are detected more often in vitro studies than in vivo studies [3].

In this study, it was found that males had more prevalence of MB2 than females. These results are similar to some studies in the literature $[7,15,33$, 42]. However, there were also studies which found no differences between genders [19, 43, 58]. The smaller detection rate of MB2 in females can be explained by demineralisation and loss of bone mass, which is three times higher in females than in males [6]. This will prevent accurate tracking of the canal by computed tomography due to lack of contrast [4].

Neaverth et al. [36] stated that the older patients had fewer MB2 canal than younger ones because of an increase in the canal calcification, tertiary dentin formation and porosity of the cortical bone. Zhang et al. [57] said that secondary dentin deposition separated a flattened canal into two canals or even create a calcified imperforate canal. In the present study, it was found that as the age progressed, the prevalence of MB2 decreased $(p<0.01)$, which is consistent with the results of Neaverth et al. [36], Thomas et al. [48], Betancourt et al. [7] and Zhang et al. [57]. For this reason, we recommend that the maxillary molar teeth be directed more attention to seeking and finding MB2 canals in the MB roots, especially in young patients. It would be very difficult to identify additional canal in the CBCT image because older people had more calcified canals and the diameter of the additional canals was smaller than the MB1 canal.

The MB2 canal is commonly located mesiopalatally to the MB1 canal [44]. The location of the MB2 canal is often indicated by in vitro studies $[17,18]$. There were only two studies that demonstrated the MB2 canal location using in vivo $C B C T[7,8]$. These studies were conducted by the same authors. They found that the MB2 canal was located in the $1 \mathrm{MM}$ $2.68 \pm 0.49 \mathrm{~mm}$ palatally and $1.25 \pm 0.34$ mesially to the MB1 canal. In the $2 \mathrm{MM}$ it was located $2.41 \pm$ $\pm 0.64 \mathrm{~mm}$ palatally and $0.98 \pm 0.33 \mathrm{~mm}$ mesially. In this study, the average distance of MB2 to the MB1 canal of the $1 \mathrm{MM}$ was $2.95 \pm 0.58 \mathrm{~mm}$ and its distance to the PP1 canal was $5.81 \pm 1.09 \mathrm{~mm}$. In the $2 \mathrm{MM}$, while the average distance to the MB1 canal was $3.08 \pm 0.67 \mathrm{~mm}$, the distance to the PP1 was $5.55 \pm 1.09 \mathrm{~mm}$. These distances were greater than reported by Betancourt et al. [8], and Gorduysus et al. [18]. Our results were similar to study conducted by Gilles et al. [17]. They found that the MB2 canal was located mesially to the MB1 canal at a distance of $2.31 \mathrm{~mm}$ in the $1 \mathrm{MM}$ and $2.06 \mathrm{~mm}$ in the $2 \mathrm{MM}$ by scanning electronic microscopy. The differences between the results may be due to differences in the techniques used, measurement techniques, or sample sizes. We believe that the inter-orifice distances can differ at different measurement levels. We measured at $1 \mathrm{~mm}$ below the pulpal floor level. Zhang et al. 
[57] reported that a larger distance ratio of MB1-PP to distobuccal (DB)-PP ( $>1.26)$ indicated a highly probable existence of an MB2 canal. They stated that $\mathrm{CBCT}$ imaging with a small voxel size is particularly important in determining the presence of an MB2 canal if clinicians fail to locate it. Since CBCT imaging is not used routinely in the diagnosis of endodontic patients, it is expected that our results will be useful for clinicians to treat teeth with MB2 canal or complex morphology potential during initial therapy.

In the literature, only two studies have reported the adjacent or contralateral formation of MB2 canals $[4,28]$. In this study, bilateral symmetry formation for the maxillary first and second molar teeth was $88 \%$ and $93 \%$, respectively. These results were similar to that reported by Alexander et al. [4]. However, these results were higher than the study of Kim et al. [28]. We found that the adjacent concurrence was $87 \%$ and $82 \%$ for the maxillary first and second molar teeth on the same side, respectively, which is approximately consistent with the results of a previous study [4]. However, the results of the present study were higher than that of Kim et al. [28] where the finding was $64 \%$. While our sample size $(n=200)$ was equal to that in the study by Alexander et al. [4]; it was lower than that in the study by Kim et al. [28] $(n=351)$. Their study was carried out about 6 years before ours. These differences may be due to improvements in CBCT software. These improvements can increase image resolution and improve diagnostic accuracy and sensitivity. To our knowledge, this is the first study to report the symmetry of the MB2 canal between contralateral and adjacent molars in a Turkish population. If an MB2 canal is found on a molar, clinicians should consider the possibility of additional canals in adjacent molars and more in contralateral molars.

However, this study had some limitations. First, our sample consisted of subjects who referred to our faculty for a dental examination. This implies that our sample was not representative of Turkish adults in general. Therefore, there is a need for studies conducted throughout our country. Second, the study had a retrospective design. Hence, it was not possible to obtain the patient's entire history. Some cultural and individual characteristics may affect the prevalence of the MB2 canal. Third, only one radiologist has evaluated the measurements. However, the intra-observer agreement values were perfect.

All procedures performed were in accordance with the ethical standards of the responsible com- mittee on human experimentation (institutional and national) and with the Helsinki Declaration of 1975, as revised in 2008.

\section{CONCLUSIONS}

In conclusion, the results of the present study indicate that the MB2 canal is found in $19.75 \%$ of the $1 \mathrm{MM}$ and $17.75 \%$ of the $2 \mathrm{MM}$. the average distance of MB2 to the MB1 canal of the $1 \mathrm{MM}$ was $2.95 \pm$ $\pm 0.58 \mathrm{~mm}$ and its distance to the PP1 canal was $5.81 \pm 1.09 \mathrm{~mm}$. In the $2 \mathrm{MM}$, while the average distance to the MB1 canal was $3.08 \pm 0.67 \mathrm{~mm}$, the distance to the PP1 was $5.55 \pm 1.09 \mathrm{~mm}$. It is important for clinicians to know the localisation and the probability of finding the MB2 canal in the first and second permanent maxilla. The occurrence possibility of these canals was also found high in the contralateral and adjacent molar teeth. CBCT imaging can facilitate the clinician to detect complex and variable root canal anatomy.

\section{REFERENCES}

1. Abarca J, Gómez B, Zaror C, et al. Assessment of mesial root morphology and frequency of MB2 canals in maxillary molars using cone beam computed tomography. Int J Morphol. 2015; 33(4): 1333-1337, doi: 10.4067/s071795022015000400023.

2. Abuabara A, Baratto-Filho F, Aguiar Anele J, et al. Efficacy of clinical and radiological methods to identify second mesiobuccal canals in maxillary first molars. Acta Odontol Scand. 2013; 71(1): 205-209, doi: 10.3109/00016357.20 11.654262, indexed in Pubmed: 22320229.

3. Alaçam T, Tinaz AC, Genç O, et al. Second mesiobuccal canal detection in maxillary first molars using microscopy and ultrasonics. Aust Endod J. 2008; 34(3): 106-109, doi: 10.1111/j.1747-4477.2007.00090.x, indexed in Pubmed: 19032644.

4. Alexander FN, Dirk H, Corne PT, et al. The prevalence of second canals in the mesiobuccal root of maxillary molars: A cone beam computed tomography study. Aust Endod J. 2018 [Epub ahead of print], doi: 10.1111/aej.12263, indexed in Pubmed: 29573065.

5. Barton DJ, Clark SJ, Eleazer PD, et al. Tuned-aperture computed tomography versus parallax analog and digital radiographic images in detecting second mesiobuccal canals in maxillary first molars. Oral Surg Oral Med Oral Pathol Oral Radiol Endod. 2003; 96(2): 223-228, doi: 10.1016/ S1079210403000611, indexed in Pubmed: 12931097.

6. Benson BW, Prihoda TJ, Glass BJ. Variations in adult cortical bone mass as measured by a panoramic mandibular index. Oral Surg Oral Med Oral Pathol. 1991; 71(3): 349-356, indexed in Pubmed: 2011361.

7. Betancourt $P$, Navarro $P$, Cantín $M$, et al. Cone-beam computed tomography study of prevalence and location of MB2 canal in the mesiobuccal root of the maxillary second molar. Int J Clin Exp Med. 2015; 8(6): 9128-9134, indexed in Pubmed: 26309568. 
8. Betancourt P, Navarro P, Muñoz G, et al. Prevalence and location of the secondary mesiobuccal canal in 1,100 maxillary molars using cone beam computed tomography. BMC Med Imaging. 2016; 16(1): 66, doi: 10.1186/s12880016-0168-2, indexed in Pubmed: 27908285.

9. Blattner TC, George N, Lee CC, et al. Efficacy of conebeam computed tomography as a modality to accurately identify the presence of second mesiobuccal canals in maxillary first and second molars: a pilot study. J Endod. 2010; 36(5): 867-870, doi: 10.1016/j.joen.2009.12.023, indexed in Pubmed: 20416435.

10. Christie WH, Thompson GK. The importance of endodontic access in locating maxillary and mandibular molar canals. J Can Dent Assoc. 1994; 60(6): 527-32, 535, indexed in Pubmed: 8032994.

11. Cotton TP, Geisler TM, Holden DT, et al. Endodontic applications of cone-beam volumetric tomography. J Endod. 2007; 33(9): 1121-1132, doi: 10.1016/j.joen.2007.06.011, indexed in Pubmed: 17931947.

12. Degerness RA, Bowles WR. Dimension, anatomy and morphology of the mesiobuccal root canal system in maxillary molars. J Endod. 2010; 36(6): 985-989, doi: 10.1016/j. joen.2010.02.017, indexed in Pubmed: 20478451.

13. Del Fabbro M, Taschieri S, Testori T, et al. Surgical versus non-surgical endodontic re-treatment for periradicular lesions. Cochrane Database Syst Rev. 2007(3): CD005511, doi: 10.1002/14651858.CD005511.pub2, indexed in Pubmed: 17636803.

14. Eder A, Kantor M, Nell A, et al. Root canal system in the mesiobuccal root of the maxillary first molar: an in vitro comparison study of computed tomography and histology. Dentomaxillofac Radiol. 2006; 35(3): 175-177, doi: 10.1259/dmfr/73909470, indexed in Pubmed: 16618851.

15. Fogel HM, Peikoff MD, Christie WH. Canal configuration in the mesiobuccal root of the maxillary first molar: a clinical study. J Endod. 1994; 20(3): 135-137, doi: 10.1016/S0099-2399(06)80059-2, indexed in Pubmed: 7996086.

16. Ghobashy AM, Nagy MM, Bayoumi AA. Evaluation of root and canal morphology of maxillary permanent molars in an egyptian population by cone-beam computed tomography. J Endod. 2017; 43(7): 1089-1092, doi: 10.1016/j. joen.2017.02.014, indexed in Pubmed: 28476465.

17. Gilles J, Reader A. An SEM investigation of the mesiolingual canal in human maxillary first and second molars. Oral Surg Oral Med Oral Pathol. 1990; 70(5): 638-643, indexed in Pubmed: 2234885.

18. Görduysus MO, Görduysus M, Friedman S. Operating microscope improves negotiation of second mesiobuccal canals in maxillary molars. J Endod. 2001; 27(11): 683-686, indexed in Pubmed: 11716081.

19. Guo J, Vahidnia A, Sedghizadeh $P$, et al. Evaluation of root and canal morphology of maxillary permanent first molars in a North American population by cone-beam computed tomography. J Endod. 2014; 40(5): 635-639, doi: 10.1016/j. joen.2014.02.002, indexed in Pubmed: 24767556.

20. Hartwell G, Bellizzi R. Clinical investigation of in vivo endodontically treated mandibular and maxillary molars. J Endod. 1982; 8(12): 555-557, doi: 10.1016/500992399(82)80016-2, indexed in Pubmed: 6962275.
21. Henry BM. The fourth canal: its incidence in maxillary first molars. J Can Dent Assoc. 1993; 59(12): 995-996, indexed in Pubmed: 8275393.

22. Ibarrola JL, Knowles KI, Ludlow MO, et al. Factors affecting the negotiability of second mesiobuccal canals in maxillary molars. J Endod. 1997; 23(4): 236-238, doi: 10.1016/ S0099-2399(97)80054-4, indexed in Pubmed: 9594773.

23. Ilgüy $D$, Ilgüy $M$, Fisekcioglu $E$, et al. Detection of jaw and root fractures using cone beam computed tomography: a case report. Dentomaxillofac Radiol. 2009; 38(3): 169-173, doi: 10.1259/dmfr/54020205, indexed in Pubmed: 19225088.

24. Imura N, Hata Gl, Toda T, et al. Two canals in mesiobuccal roots of maxillary molars. Int Endod J. 1998; 31(6): 410-414, indexed in Pubmed: 15551608.

25. Parker J, Mol A, Rivera EM, et al. CBCT uses in clinical endodontics: the effect of $C B C T$ on the ability to locate MB2 canals in maxillary molars. Int Endod J. 2017; 50(12): 1109-1115, doi: 10.1111/iej.12736, indexed in Pubmed: 27977863.

26. Karaman GT, Onay EO, Ungor M, et al. Evaluating the potential key factors in assessing the morphology of mesiobuccal canal in maxillary first and second molars. Aust Endod J. 2011; 37(3): 134-140, doi: 10.1111/j.17474477.2010.00240.x, indexed in Pubmed: 22117721.

27. Kim Y, Chang SW, Lee JK, et al. A micro-computed tomography study of canal configuration of multiple-canalled mesiobuccal root of maxillary first molar. Clin Oral Investig. 2013; 17(6): 1541-1546, doi: 10.1007/s00784-012-08528, indexed in Pubmed: 23053704.

28. Kim Y, Lee SJ, Woo J. Morphology of maxillary first and second molars analyzed by cone-beam computed tomography in a korean population: variations in the number of roots and canals and the incidence of fusion. J Endod. 2012; 38(8): 1063-1068, doi: 10.1016/j.joen.2012.04.025, indexed in Pubmed: 22794206.

29. Kontakiotis EG, Tzanetakis GN. Four canals in the mesial root of a mandibular first molar. A case report under the operating microscope. Aust Endod J. 2007; 33(2): 84-88, doi: 10.1111/j.1747-4477.2007.00068.x, indexed in Pubmed: 17697250.

30. Kottoor J, Velmurugan N, Sudha R, et al. Maxillary first molar with seven root canals diagnosed with cone-beam computed tomography scanning: a case report. J Endod. 2010; 36(5): 915-921, doi: 10.1016/j.joen.2009.12.015, indexed in Pubmed: 20416446.

31. Kulild JC, Peters DD. Incidence and configuration of canal systems in the mesiobuccal root of maxillary first and second molars. J Endod. 1990; 16(7): 311-317, indexed in Pubmed: 2081944.

32. La SH, Jung DH, Kim EC, et al. Identification of independent middle mesial canal in mandibular first molar using cone-beam computed tomography imaging. J Endod. 2010; 36(3): 542-545, doi: 10.1016/j.joen.2009.11.008, indexed in Pubmed: 20171380.

33. Lee JH, Kim KD, Lee JK, et al. Mesiobuccal root canal anatomy of Korean maxillary first and second molars by cone-beam computed tomography. Oral Surg Oral Med Oral Pathol Oral Radiol Endod. 2011; 111(6): 785-791, doi: 10.1016/j.tripleo.2010.11.026, indexed in Pubmed: 21439860. 
34. Lofthag-Hansen S, Huumonen S, Gröndahl K, et al. Limited cone-beam $\mathrm{CT}$ and intraoral radiography for the diagnosis of periapical pathology. Oral Surg Oral Med Oral Pathol Oral Radiol Endod. 2007; 103(1): 114-119, doi: 10.1016/j. tripleo.2006.01.001, indexed in Pubmed: 17178504.

35. Nattress BR, Martin DM. Predictability of radiographic diagnosis of variations in root canal anatomy in mandibular incisor and premolar teeth. Int Endod J. 1991; 24(2): 58-62, indexed in Pubmed: 1917090.

36. Neaverth EJ, Kotler LM, Kaltenbach RF. Clinical investigation (in vivo) of endodontically treated maxillary first molars. J Endod. 1987; 13(10): 506-512, doi: 10.1016/ S0099-2399(87)80018-3, indexed in Pubmed: 3482228.

37. Neelakantan P, Subbarao C, Ahuja R, et al. Cone-beam computed tomography study of root and canal morphology of maxillary first and second molars in an Indian population. J Endod. 2010; 36(10): 1622-1627, doi: 10.1016/j. joen.2010.07.006, indexed in Pubmed: 20850665.

38. Parker J, Mol A, Rivera EM, et al. CBCT uses in clinical endodontics: the effect of $C B C T$ on the ability to locate MB2 canals in maxillary molars. Int Endod J. 2017; 50(12): 1109-1115, doi: 10.1111/iej.12736, indexed in Pubmed: 27977863.

39. Patel S, Dawood A, Whaites E, et al. New dimensions in endodontic imaging: part 1. Conventional and alternative radiographic systems. Int Endod J. 2009; 42(6): 447-462, doi: 10.1111/j.1365-2591.2008.01530.x, indexed in Pubmed: 19298577.

40. Pattanshetti N, Gaidhane M, Al Kandari AM. Root and canal morphology of the mesiobuccal and distal roots of permanent first molars in a Kuwait population--a clinical study. Int Endod J. 2008; 41(9): 755-762, doi: 10.1111/j.13652591.2008.01427.x, indexed in Pubmed: 18637850.

41. Peeters HH, Suardita K, Setijanto D. Prevalence of a second canal in the mesiobuccal root of permanent maxillary first molars from an Indonesian population. J Oral Sci. 2011; 53(4): 489-494, indexed in Pubmed: 22167035.

42. Ratanajirasut R, Panichuttra A, Panmekiate S. A cone-beam computed tomographic study of root and canal morphology of maxillary first and second permanent molars in a thai population. J Endod. 2018; 44(1): 56-61, doi: 10.1016/j. joen.2017.08.020, indexed in Pubmed: 29061352.

43. Reis AG, Grazziotin-Soares R, Barletta FB, et al. Second canal in mesiobuccal root of maxillary molars is correlated with root third and patient age: a cone-beam computed tomographic study. J Endod. 2013; 39(5): 588-592, doi: 10.1016/j. joen.2013.01.003, indexed in Pubmed: 23611373.

44. Schwarze T, Baethge $C$, Stecher $T$, et al. Identification of second canals in the mesiobuccal root of maxillary first and second molars using magnifying loupes or an operating microscope. Aust Endod J. 2002; 28(2): 57-60, indexed in Pubmed: 12360670.

45. Silva EJ, Nejaim Y, Silva AIV, et al. Evaluation of root canal configuration of maxillary molars in a Brazilian population using cone-beam computed tomographic imaging: an in vivo study. J Endod. 2014; 40(2): 173-176, doi: 10.1016/j. joen.2013.10.002, indexed in Pubmed: 24461399.

46. Stropko JJ. Canal morphology of maxillary molars: clinical observations of canal configurations. J Endod. 1999; 25(6):
446-450, doi: 10.1016/50099-2399(99)80276-3, indexed in Pubmed: 10530248.

47. Studebaker B, Hollender L, Mancl L, et al. The Incidence of Second Mesiobuccal Canals Located in Maxillary Molars with the Aid of Cone-beam Computed Tomography. J Endod. 2018; 44(4): 565-570, doi: 10.1016/j. joen.2017.08.026, indexed in Pubmed: 29153734.

48. Thomas RP, Moule AJ, Bryant R. Root canal morphology of maxillary permanent first molar teeth at various ages. Int Endod J. 1993; 26(5): 257-267, indexed in Pubmed: 8300257.

49. Tian XM, Yang XW, Qian L, et al. Analysis of the root and canal morphologies in maxillary first and second molars in a chinese population using cone-beam computed tomography. J Endod. 2016; 42(5): 696-701, doi: 10.1016/j. joen.2016.01.017, indexed in Pubmed: 26994598.

50. Vasundhara V, Lashkari KP. An study to find the incidence of mesiobuccal 2 canal in permanent maxillary first molars using three different methods. J Conserv Dent. 2017; 20(3): 190-193, doi: 10.4103/0972-0707.218308, indexed in Pubmed: 29279624.

51. Verma P, Love RM. A Micro CT study of the mesiobuccal root canal morphology of the maxillary first molar tooth. Int Endod J. 2011; 44(3): 210-217, doi: 10.1111/j.13652591.2010.01800.x, indexed in Pubmed: 20880136.

52. Vertucci FJ. Root canal anatomy of the human permanent teeth. Oral Surg Oral Med Oral Pathol. 1984; 58(5): 589-599, indexed in Pubmed: 6595621.

53. Weine FS, Healey HJ, Gerstein H, et al. Canal configuration in the mesiobuccal root of the maxillary first molar and its endodontic significance. 1969. J Endod. 2012; 38(10): 1305-1308, doi: 10.1016/j.joen.2012.08.005, indexed in Pubmed: 22980167.

54. Weissman J, Johnson JD, Anderson M, et al. Association between the presence of apical periodontitis and clinical symptoms in endodontic patients using cone-beam computed tomography and periapical radiographs. J Endod. 2015; 41(11): 1824-1829, doi: 10.1016/j. joen.2015.06.004, indexed in Pubmed: 26349581.

55. Weng XL, Yu SB, Zhao SL, et al. Root canal morphology of permanent maxillary teeth in the Han nationality in Chinese Guanzhong area: a new modified root canal staining technique. J Endod. 2009; 35(5): 651-656, doi: 10.1016/j. joen.2009.02.010, indexed in Pubmed: 19410077.

56. Zhang $R$, Yang $H$, Yu $X$, et al. Use of $C B C T$ to identify the morphology of maxillary permanent molar teeth in a Chinese subpopulation. Int Endod J. 2011; 44(2): 162-169, doi: 10.1111/j.1365-2591.2010.01826.x, indexed in Pubmed: 21091495.

57. Zhang $Y, X u H$, Wang $D$, et al. Assessment of the second mesiobuccal root canal in maxillary first molars: a conebeam computed tomographic study. J Endod. 2017; 43(12): 1990-1996, doi: 10.1016/j.joen.2017.06.021, indexed in Pubmed: 29032819.

58. Zheng Qh, Wang Y, Zhou Xd, et al. A cone-beam computed tomography study of maxillary first permanent molar root and canal morphology in a Chinese population. J Endod. 2010; 36(9): 1480-1484, doi: 10.1016/j.joen.2010.06.018, indexed in Pubmed: 20728713. 